\title{
A Narrative Review of Respiratory Impairment, Assessment, and Rehabilitation in Multiple Sclerosis
}

\author{
Muge Dereli $^{a}$ Buse Ozcan Kahraman ${ }^{b}$ Turhan Kahraman ${ }^{c}$ \\ aDepartment of Physiotherapy and Rehabilitation, Graduate School of Health Sciences, Izmir Katip Celebi

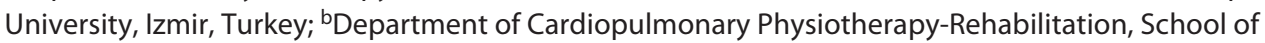 \\ Physical Therapy and Rehabilitation, Dokuz Eylül University, Izmir, Turkey; 'Department of Physiotherapy \\ and Rehabilitation, Faculty of Health Sciences, Izmir Katip Celebi University, Izmir, Turkey
}

\section{Keywords}

Multiple sclerosis · Respiratory dysfunction · Assessment ·

Rehabilitation

\section{Abstract}

Background: Respiratory impairment is a problem seen in people with multiple sclerosis (pwMS) from the early stages of the disease but not frequently recognized by clinicians until the later stages. It is seen in different ways, such as respiratory muscle weakness, change in pulmonary volumes, and decrease in cough efficiency. This situation has consequences affecting individuals' physical fitness, participation in daily life, and quality of life. Summary: This review explains possible respiratory impairment mechanisms, related problems, assessment, and rehabilitation approaches in pwMS. Key Messages: It is recommended a comprehensive assessment of respiratory functions in pwMS regardless of the disease severity and stage. In addition, pulmonary rehabilitation and other exercises can have positive effects on the respiratory functions of pwMS. In future studies, specific training parameters should be determined for pwMS to achieve optimal benefits. There is also a need for studies karger@karger.com www.karger.com/dmj

Karger $\stackrel{\text { ' }}{5}$
(C) 2022 The Author(s)

Published by S. Karger AG, Basel

This is an Open Access article licensed under the Creative Commons Attribution-NonCommercial-4.0 International License (CC BY-NC) (http://www.karger.com/Services/OpenAccessLicense), applicable to the online version of the article only. Usage and distribution for commercial purposes requires written permission. that apply respiratory muscle training in pwMS who have a high disease severity and limited participation in the activities of daily living.

(c) 2022 The Author(s)

Published by S. Karger AG, Basel

\section{Introduction}

Multiple sclerosis (MS) is an inflammatory demyelinating disease of the central nervous system predominantly diagnosed in young adults [1]. It is estimated globally to be about 2.8 million people with MS (pwMS) [2]. These individuals are confronted with various serious symptoms such as spasticity, muscle weakness, gait disturbance, cognitive impairment, swallowing problems, and bladder-bowel dysfunction $[3,4]$. In addition, the pulmonary system can be impaired, but healthcare providers usually overlook its assessment due to the high prevalence of other MS symptoms. However, respiratory functions and respiratory muscle strength have been altered even in the early stages of MS, and these changes become exacerbated by the increased disability [5]. The risk of respiratory death is almost 12 times higher, and this rate ac-

Correspondence to:

Muge Dereli, mugedereli97@gmail.com 


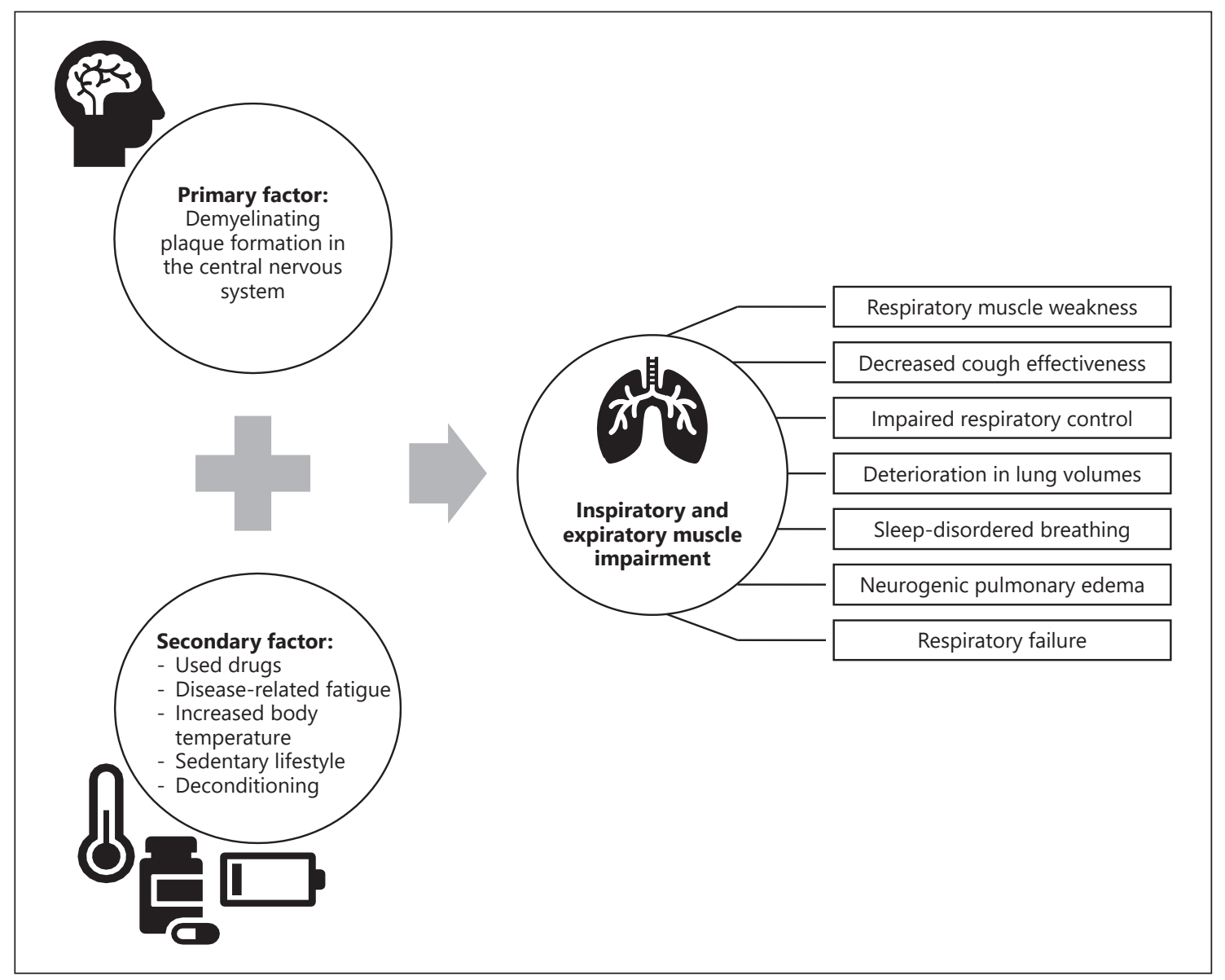

Fig. 1. Pulmonary system affecting mechanism in MS: the function of respiratory muscles is deteriorated primarily by the formation of demyelinated plaques in the central nervous system and accompanied by secondary factors (drugs, fatigue, increased body temperature, sedentary lifestyle, and deconditioning). This impairment manifests in different ways, such as decreased respiratory muscle strength, lung volumes, and cough efficiency.

counts for approximately $47 \%$ of all causes of death in MS [6]. The pulmonary system's involvement which is generally observed deterioration in diffusion capacity (DLCO), respiratory muscle strength, and ventilation-perfusion ratio (V/Q) [7] leads to exercise intolerance, hospitalization, and morbidity in pwMS. As a result, the physical fitness level of pwMS deteriorates, and it becomes more difficult for them to participate in daily activities [8].

Previous research has compiled information about pulmonary dysfunction, assessment, and treatment in MS [9]. Due to substantial developments that have been achieved on this topic, it is thought that a current review will contribute to studies related to MS. The current narrative review aimed to explain respiratory involvement, including respiratory failure, respiratory muscle weakness, cough inefficacy, sleep breathing disorders, and respiratory dysfunction during exercise. Furthermore, it is aimed to present respiratory assessment tools and the results of rehabilitation programs for the pulmonary system in pwMS.

\section{Underlying Mechanisms of the Respiratory Impairment}

The brain stem and spinal cord contain relevant centers that generate signals to regulate respiratory muscles' functioning. Depending on the size and area of demyelinating plaques that develop in these respiratory centers, respiratory muscle-related impulses could be disrupted in pwMS [10]. Therefore, one or more symptoms such as respiratory muscle weakness, dyspnea, ineffective cough, bulbar dysfunction, and decreased respiratory control are seen in varying severity [11]. Although pulmonary in- 
volvement in the early stages of MS is uncommon, pulmonary issues' prevalence increases with exacerbated disease severity [10]. Medication, fatigue, and high body temperature leading to interruption of nerve conduction may adversely affect the respiratory muscles and enhance the possibility of respiratory dysfunctions. The occurrence of pulmonary system impairment and resulting problems in MS are summarized in Figure 1.

\section{Respiratory Failure}

Respiratory failure occurs as a consequence of demyelinated plaque formation at the cervical spinal cord, as well as in the terminal stage of MS when respiratory muscles and cough efficiency are severely affected. Even if an acute respiratory failure is seen rarely in MS, it is quite common in quadriplegic and paraplegic pwMS. Moreover, the risk of acute respiratory failure enhances in relapsing-remitting MS following new, large plaque formation in the brain stem [12]. Individuals with relapsingremitting MS can develop dyspnea, orthopnea, confusion within hours and minutes, or rapid, shallow breathing associated with diaphragm weakness. The vital capacity (VC) also decreases by more than $30 \%$ during the transition from lying down to sitting upright [12]. Chronic respiratory failure is seen at the advanced stages of MS or pwMS who use wheelchair with weak upper extremities and respiratory muscles $[11,13]$.

\section{Respiratory Muscle Weakness}

Respiratory muscle weakness is the most common respiratory problem in pwMS, especially in bedridden people or people who use wheelchairs [14]. Even if respiratory muscle weakness is more common in advanced stages of MS, respiratory muscles weaken asymptomatically from the early stage. Expiratory muscle weakness is more predominant in MS because expiratory muscles are primarily involved [15]. Although respiratory muscle strengths are normal in pwMS with moderate disease severity, these values can differ greatly between individuals, indicating lower respiratory muscle strength in some individuals [16]. pwMS with significant expiratory muscle weakness have lower functional exercise capacity and higher disability levels [16].

Multiple factors are influential to the detriment of the respiratory muscles in MS; however, the corruption of the neural tract related to respiratory muscles is most effective. In addition, sedentary lifestyle, deconditioning, fatigue, malnutrition, steroid-related myopathy, disrupted respiratory activation and coordination, bulbar dysfunction, and facial paralysis contribute to weakness $[15,17]$.
The progression of paralysis from distal to proximal in MS causes weakness of the expiratory muscles, the rectus abdominis, and transversus abdominis, before the diaphragm and intercostal muscles [18]. Likewise, respiratory muscle endurance and maximum inspiratory muscle strength progressively decline in line with the patient's ambulation ability [13].

Weakened respiratory muscle leads to general muscle weakness, spasticity, fatigue, and cognitive dysfunction $[11,19]$, except for issues associated with the pulmonary system like decreased lung volumes, ventilation-cough inefficiency, inadequate airway clearance, and sleep-disorder breathing [6]. It has also been reported that respiratory muscle endurance is significantly related to sleep quality and functional exercise capacity in pwMS [19].

The pelvic floor, the diaphragm responsible for inspiration, and the abdominal muscles responsible for expiration generate the trunk stabilizing system. This system provides postural adjustments by regulating intra-abdominal pressure during static and dynamic activities [20]. It has been reported that urinary and gait functions are more impaired in pwMS whose respiratory muscle strength and respiratory functions are affected. In particular, a higher correlation was found between expiratory muscle strength and urinary incontinence and physical dysfunctions [21]. The simultaneous activation of these muscle groups and the presence of a biomechanical connection among trunk stabilizing system components explain the relation between respiratory muscle strength and urinary incontinence [21].

\section{Decreased Cough Efficiency}

Cough efficiency is a vital function responsible for the clearance of secretions in airways. Bulbar dysfunction, delayed glottis closure, and decreased intrathoracic pressure accordingly with expiratory muscle weakness reduce cough efficiency in pwMS. Cough inefficiency accumulates secretions in their airways, and therefore, it might lead to atelectasis and pneumonia in the future [22]. It has been shown that there is a correlation between peak cough flow (PCF), which is a parameter for indicating cough efficiency, and disease severity in pwMS [22]. A study examining pwMS who use wheelchairs found that PCF was reduced in $61.6 \%$ of these individuals, and PCF was severely affected in $37 \%$ of them [23].

\section{Impaired Respiratory Control}

Respiratory control is provided by respiratory centers located in the pons and medulla. There are two respiratory centers called dorsal and ventral groups controlled 
by the pneumotoxic and apneumatic respiratory centers in the pons. While the dorsal respiratory center is responsible for inspiration and respiratory rhythm, the ventral respiratory center is responsible for active expiration in conditions where ventilation must be increased, like physical exercise. When one of those respiratory centers is affected by MS, respiratory control is destroyed, and then respiratory control difficulties might emerge as paroxysmal ventilation, loss of voluntary or autonomic respiratory control, or apneumatic breathing $[13,24]$.

\section{Sleep-Disordered Breathing}

pwMS experience three different respiratory disorders during sleep: obstructive sleep apnea (OSA), central sleep apnea linked with demyelination in the medulla, and nocturnal hypoventilation linked with decreased tidal volume (Vt) in REM sleep. Obstructive and central sleep apneas usually occur in cases with brain stem involvement $[25,26]$.

Sleep-disordered breathing might conclude inability to fall asleep, insomnia, daytime sleepiness, loss of concentration, and tiredness. It is important to note that sleep disorder breathing-related fatigue should be distinguished from MS-related fatigue [25, 26]. It has also been reported that perceived fatigue is a substantial predictor of OSA in pwMS [27].

OSA, which is estimated to be about $33 \%$ in pwMS, is a potential risk factor for cognitive dysfunction [28]. A study investigated the potential impact of OSA treatment on cognition and concluded that verbal learning significantly improved in pwMS who received treatment [29]. Given these outcomes, there is a need to further investigation for improvement of cognitive function and fatigue in MS through the treatment of sleep-disordered breathing.

\section{Neurogenic Pulmonary Edema}

Neurogenic pulmonary edema, which occasionally emerges as the first symptom, is a rare condition in pwMS. Although the pathophysiology of neurogenic pulmonary edema has not been precisely explained, it has been reported that it may be associated with a defect in the tractus solitarius, which is responsible for pulmonary hydrostatic pressure [30]. The affected tractus solitarius induces pulmonary hydrostatic pressure via increasing sympathetic impulses and resulting in pulmonary edema [30].

\section{Deterioration in Lung Volumes}

Alteration in pulmonary volumes usually occurs following respiratory muscle weakness [13]. While respira- tory muscle strength is affected mildly or moderately, these volumes could be at normative values in MS [13]. It has been reported that resting pulmonary volumes are associated with exercise tolerance in MS [31], but similarly, pulmonary volumes are not associated with disability levels [16].

The VC can vary depending on postural changes and disability levels in pwMS. For instance, the VC value decreases by $10-30 \%$ when shifting from upright to supine; it is about $102 \%$ of the predicted VC in pwMS with a lower disability [13]. Besides, this value is lower than both bedridden people (62\% predicted) and ( $82 \%$ predicted) pwMS who use wheelchairs [13]. The current research has reported a decrease of $\mathrm{VC}$ in $72.6 \%$ of wheelchairbounded pwMS and a significant correlation between VC and disease severity [23].

\section{Respiratory Function during Exercise}

During submaximal or endurance exercise, remarkable alteration occurs in the respiratory functions of pwMS, such as an impaired pulmonary gas exchange. The carbon dioxide ventilation equivalent and the oxygen ventilation equivalent values which are the indicators of pulmonary gas exchange are enhanced during submaximal exercise. Change in these values means ventilatory gas exchange is reduced. The end-tidal oxygen pressure value rises through the endurance exercise, and the endtidal carbon dioxide pressure value declines. This stands for that the V/Q is disturbed. Apart from these, the physiological dead space/Vt ratio increases, and oxygen saturation and DLCO decrease during exercise [31].

When pulmonary system issues (related to diffusion, ventilatory gas exchange, diaphragm function, and respiratory rhythm) are accompanied by cardiovascular dysfunction, the V/Q is impaired, resulting in lower oxygen levels in pwMS throughout physical exercise. It has also been reported that these respiratory dysfunctions are associated with perceived exertion, exhaustion, and exercise tolerance [32].

\section{Outcome Measures Evaluating the Respiratory Function}

Pulmonary function tests, which could guide the physician by providing information about the pulmonary system's components, include assessment methods for monitoring and managing pwMS who are diagnosed or not [33]. To provide a better viewpoint, the pulmonary system evaluation in pwMS is categorized according to 


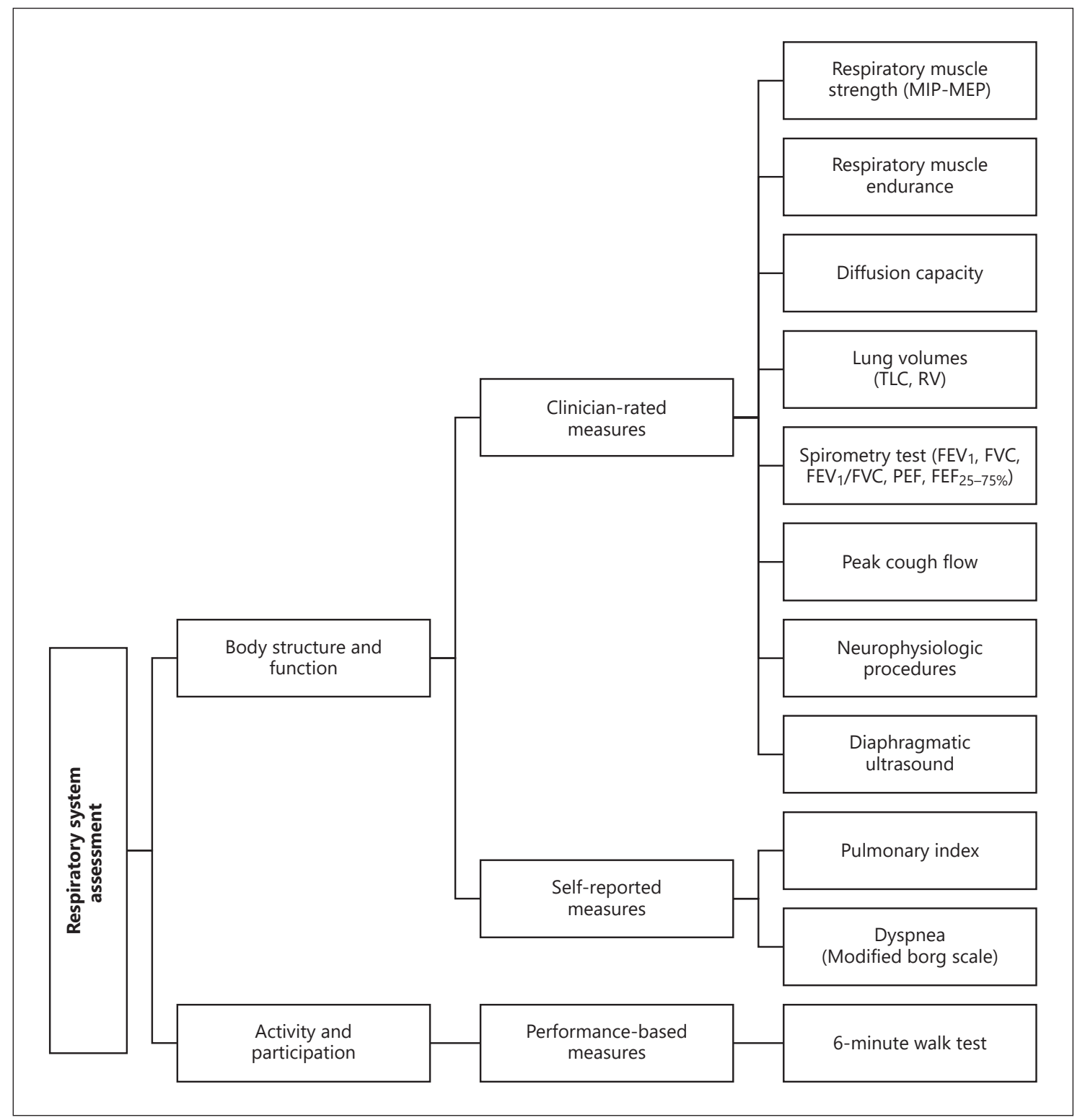

Fig. 2. Respiratory system assessment in pwMS according to the ICF: an overview of each component of ICF (body structure and function; activity and participation) under the subheadings of clinician-rated measures, selfreported measures, and performance-based measures. TLC, total lung capacity; $\mathrm{FEV}_{1} / \mathrm{FVC}$, the ratio of the $\mathrm{FEV}_{1}$ to FVC volumes; $\mathrm{FEF}_{25-75 \%}$, maximum flow rates between 25 and $75 \%$ of VC; ICF, International Classification of Functioning, Disability, and Health.

the International Classification of Functioning, Disability, and Health framework (Fig. 2).

\section{Respiratory Muscle Function}

Respiratory muscle function is commonly assessed by maximal inspiratory pressure (MIP) and maximal expiratory pressure (MEP) in pwMS. Inspiratory mouth pressure is a method that requires generating as much pres- sure as possible against a closed mouthpiece and reflects the inspiratory muscle function. Expiratory mouth pressure, created by the Valsalva maneuver against the closed mouthpiece in total pulmonary capacity, is a method that reflects expiratory muscle function. The strength of the abdominal, auxiliary respiratory muscles and the lung's elastic recoil affect the expiratory mouth pressure value [18]. 
Compared with the values expected from the healthy general population, MIP decreased significantly by $77 \%$ $( \pm 23)$ and MEP by $60 \%( \pm 13)$ in pwMS [14]. When pwMS with low (0-2) and moderate (2.5-4.5) disability levels were compared with healthy individuals, it was observed that MEP was significantly reduced in pwMS with low $\left(112.43 \pm 23.33 \mathrm{~cm} \mathrm{H}_{2} 0\right)$ and moderate $(98.89 \pm 27.81 \mathrm{~cm}$ $\mathrm{H}_{2} 0$ ) disability. On the other hand, although MIP decreased in all patients compared to healthy individuals, MIP value decreased significantly only in patients with moderate disability $\left(84.00 \pm 17.06 \mathrm{~cm} \mathrm{H}_{2} 0\right)$ [5]. In a recent study, it has been reported that respiratory muscle strength was normal on a group level in pwMS with a moderate disease course (4.0-6.5), but these values differed largely between individuals. The MIP values ranged from 26 to 143 (mean $80 \pm 28$ ) $\mathrm{cm} \mathrm{H}_{2} \mathrm{O}(98 \pm 31 \%$ predicted), and the MEP values ranged from 43 to 166 (mean $97 \pm 25) \mathrm{cm} \mathrm{H}_{2} \mathrm{O}(104 \pm 29 \%$ predicted $)$ in this study [16].

It has been reported that there is a moderate correlation between respiratory muscle strength and urinary function, more in expiratory muscle strength. In addition, a similar relation was found between expiratory muscle strength and physical functions evaluated with the timed up and go test and Barthel Index in pwMS [21].

\section{Spirometry Test}

The spirometry test, which is a more utilized method for lung function assessment, is easily performed by an exhalation as quickly as possible following maximum inhalation. The forced expiratory volume in $1 \mathrm{~s}\left(\mathrm{FEV}_{1}\right)$, the forced VC (FVC), and the ratio of $\mathrm{FEV}_{1}$ to $\mathrm{FVC}$ are used to determine obstructive or restrictive ventilation problems [33]. Other tests are the peak expiratory flow (PEF) during expiration, maximum flow rates between 25 and $75 \%$ of VC that reflect the condition of small airways, and the maximum voluntary ventilation (MVV), stating the respiratory muscle endurance [33]. MVV is also used in estimating breathing reserve during maximal exercise. There is a significant correlation between MVV and $\mathrm{FEV}_{1}$; therefore, MVV might not be included in the set of lung function parameters [34]. In case of a disproportionate decrease in MVV relative to $\mathrm{FEV}_{1}$ [34], both parameters should be included in the spirometry test in MS.

A study has reported that obstructive pulmonary disorder, a condition in which the ratio of $\mathrm{FEV}_{1}$ to $\mathrm{FVC}$ or maximum flow rate value between 25 and $75 \%$ of VC decreased, was seen in $52.17 \%$ of pwMS without disability or with minimal disability and $50 \%$ of pwMS with mild to severe disability. Likewise, it has been determined that participants' PEF values decreased [5]. A recent study presented a significant positive correlation between pulmonary function variables (VC, FVC, $\mathrm{FEV}_{1}$, and PEF) and respiratory muscle strengths, besides moderate correlation between PEF and the 6-min walk distance in pwMS with moderate disability [16]. Although VC and $\mathrm{FEV}_{1}$ were normal in these patients, PEF was in the lower limit of normal [16].

\section{Lung Volumes}

The residual volume (RV), briefly defined as the dead air space, reflects the volume of air remaining in the lungs at the end of maximum expiration [33]. RV can be increased significantly in pwMS in case if the air in the lungs is not completely discharged [13]. The total lung capacity, the sum of RV and VC, is recognized as the total air volume at the end of maximum inspiration [33]. As with restrictive pulmonary disorders, total lung capacity tends to decrease in MS [13].

\section{Diffusion Capacity}

DLCO, reflecting the gas dispersed across the alveolar membrane, provides knowledge about the alveolar membrane's integrity and dimension. It is determined by calculating the remaining carbon monoxide amount because of exhaling whole air after taking a rapid breath. It has been stated that DLCO can be impaired with respiratory muscle and other lung volumes or decreased due to fingolimod medication in MS [35].

\section{Peak Cough Flow}

PCF is directly related to expiratory muscle strength and cough effectiveness [36]. It has been reported that in pwMS who have both pulmonary dysfunction and cough inefficacy, PCF value improves, and the decline rate of FVC and PCF slows down after lung volume recruitment [37].

\section{Neurophysiologic Procedures}

Magnetic transcranial-cervical stimulation and electrical stimulation are the tools employing motor evoked potentials of the phrenic nerve to evaluate pulmonary functions. Central motor conduction time between cortex and diaphragm can be measured by this method. Despite the absence of respiratory disturbance, the diaphragm's electrophysiological evaluation can surprisingly result in increment motor evoked potential and central motor conduction time in pwMS [38].

\section{Diaphragmatic Ultrasound}

Diaphragmatic ultrasound is a practical, noninvasive technique to assess diaphragm thickness and mo- 
Table 1. Overview of the studies on RMT in pwMS

\begin{tabular}{|c|c|c|c|c|c|c|}
\hline Study & Sample size & MS course & EDDS score & Interventions & $\begin{array}{l}\text { Intensity, frequency, } \\
\text { and duration }\end{array}$ & Main results \\
\hline $\begin{array}{l}\text { Gosselink et al. } \\
\text { [42] (RCT) }\end{array}$ & $\begin{array}{l}28 \text { pwMS } \\
\text { Intervention } \\
(n=9) \\
\text { Control }(n=9)\end{array}$ & NR & $\begin{array}{l}\text { Range: } 6.5-9.5 \\
\text { Median: } 8.5\end{array}$ & $\begin{array}{l}\text { EMT (control } \\
\text { group: } \\
\text { breathing } \\
\text { exercise) }\end{array}$ & $\begin{array}{l}60 \% \text { MEP } \\
3 \text { sets } \\
15 \text { repetitions } \\
2 \text { times/day }\end{array}$ & $\begin{array}{l}\text { MIP, MEP } \uparrow \text { (more in the EMT } \\
\text { group than control) } \\
\text { Cough efficiency (PI) } \uparrow \text { (more } \\
\text { in EMT group than control) }\end{array}$ \\
\hline $\begin{array}{l}\text { Chiara et al. [41] } \\
(\mathrm{RCT})\end{array}$ & $\begin{array}{l}\text { pwMS }(n=17) \\
\text { Healthy } \\
\text { control }(n=14)\end{array}$ & NR & $\begin{array}{l}\text { Range: } 1.5-6.5 \\
\text { Mean (SD): } 3.62 \text { (1.31) }\end{array}$ & EMT & $\begin{array}{l}40-80 \% \text { MEP } \\
4 \text { sets } \\
6 \text { repetitions } \\
5 \text { days/week } \\
8 \text { weeks training } \\
4 \text { weeks detraining }\end{array}$ & $\begin{array}{l}\text { MEP, PEF } \uparrow \text { (in pwMS) } \\
\text { Maximal voluntary cough } \leftrightarrow \\
\text { (in pwMS) }\end{array}$ \\
\hline $\begin{array}{l}\text { Pfalzer and } \\
\text { Fry [47] (RCT) }\end{array}$ & $\begin{array}{l}46 \text { pwMS } \\
\text { Intervention } \\
(n=20) \\
\text { Nontreatment } \\
\text { control }(n=19)\end{array}$ & $\begin{array}{l}\text { RRMS }(n=22) \\
\text { PPMS }(n=5) \\
\text { SPMS }(n=5) \\
\text { PRMS }(n=3) \\
\text { Unknown }(n=4)\end{array}$ & $\begin{array}{l}\text { Intervention group = } \\
\text { Range: } 2.0-6.5 \\
\text { Mean (SD): } 4.1(1.9) \\
\text { Control group = } \\
\text { Range: } 2.0-6.5 \\
\text { Mean (SD): } 3.2(1.2)\end{array}$ & $\mathrm{IMT}$ & $\begin{array}{l}60 \% \text { MIP } \\
3 \text { sets } \\
15 \text { repetitions } \\
10-15 \text { min/day } \\
10 \text { weeks home-based } \\
\text { training }\end{array}$ & $\begin{array}{l}\text { MIP } \uparrow \text { (more in the IMT group } \\
\text { than control) } \\
\text { MEP, MVV } \uparrow \text { (no group } \\
\text { difference) } \\
\text { Timed balance scores } \uparrow \text { (more } \\
\text { in the IMT group than control) } \\
\text { 6-MWT } \uparrow \text { (no group difference) }\end{array}$ \\
\hline $\begin{array}{l}\text { Ray et al. [40] } \\
(\mathrm{RCT})\end{array}$ & $\begin{array}{l}21 \text { pwMS } \\
\text { Intervention } \\
(n=11) \\
\text { Nontreatment } \\
\text { control }(n=10)\end{array}$ & NR & $\begin{array}{l}\text { Intervention group = } \\
\text { Range: } 1.0-6.5 \\
\text { Mean (SD): } 3.2(1.9) \\
\text { Control group = } \\
\text { Range: } 1.0-6.0 \\
\text { Mean (SD): } 4.4(2.1)\end{array}$ & IMT + EMT & $\begin{array}{l}25-50 \% \text { MIP-MEP } \\
30 \text { min/session } \\
3 \text { days/week (only } 1 \\
\text { day at the clinic) } \\
5 \text { weeks training }\end{array}$ & $\begin{array}{l}\text { MIP, MEP } \uparrow \text { (more in the RMT } \\
\text { group than control) } \\
\text { MFIS } \downarrow \text { (more in the RMT } \\
\text { group than control) } \\
\text { 6-MWT, timed stair climb, } \\
\text { PADS, and MSSE } \leftrightarrow \text { (neither } \\
\text { group showed changes) } \\
\text { SF-36 (decreased emotional } \\
\text { well-being and general health } \\
\text { in the control group; } \\
\text { increased energy/fatigue and } \\
\text { general health in RMT) }\end{array}$ \\
\hline $\begin{array}{l}\text { Silverman et al. } \\
{[44](R C T)}\end{array}$ & $\begin{array}{l}42 \text { pwMS } \\
\text { Intervention } \\
(n=20) \\
\text { Sham }(n=14)\end{array}$ & NR & $\begin{array}{l}\text { Intervention group = } \\
\text { Range: } 2.5-8.0 \\
\text { Mean (SD): } 5.5(1.5) \\
\text { Sham group = } \\
\text { Range: } 2.0-8.5 \\
\text { Mean (SD): } 5.48(1.7)\end{array}$ & EMT & $\begin{array}{l}75 \% \text { MEP (sham: } 0 \% \\
\text { MEP) } \\
5 \text { sets } \\
5 \text { repetitions } \\
20 \text { min/day } \\
5 \text { days/week } \\
5 \text { weeks training }\end{array}$ & $\begin{array}{l}\text { MEP } \uparrow \text { (no group difference) } \\
\text { SWAL-QOL } \uparrow \text { (except for } \\
\text { burden and pharyngeal } \\
\text { swallow symptom status, no } \\
\text { group difference) } \\
\text { PAS } \downarrow \text { (more in the EMT group } \\
\text { than sham) }\end{array}$ \\
\hline $\begin{array}{l}\text { Huang et al. } \\
\text { [43] } \\
\text { (within-subjects } \\
\text { design) }\end{array}$ & 37 pwMS & NR & $\begin{array}{l}\text { Range: } 8.0-9.5 \\
\text { Mean (SD): } 8.5(0.4)\end{array}$ & IMT & $\begin{array}{l}\% 30 \text { MIP } \\
3 \text { sets } \\
15 \text { repetitions } \\
7 \text { days/week } \\
10 \text { weeks training }\end{array}$ & $\begin{array}{l}\mathrm{MIP} \uparrow \\
\mathrm{MEP} \leftrightarrow\end{array}$ \\
\hline $\begin{array}{l}\text { Martin-Sanchez } \\
\text { et al. [45] } \\
\text { (non- } \\
\text { randomized, } \\
\text { double-blind, } \\
\text { controlled trial) }\end{array}$ & $\begin{array}{l}67 \text { pwMS } \\
\text { Intervention } \\
(n=36) \\
\text { Respiratory } \\
\text { exercise group } \\
(n=31)\end{array}$ & $\begin{array}{l}\operatorname{RRMS}(n=49) \\
\operatorname{PPMS}(n=2) \\
\operatorname{SPMS}(n=16)\end{array}$ & $\begin{array}{l}\text { Range: } 2.0-8.5 \\
\text { Median: } 6 \\
\text { Mean (SD): } 5.35(2.30) \\
\text { Intervention group = } \\
\text { Mean (SD): } 5.21(2.36) \\
\text { Control group = } \\
\text { Mean (SD): } 5.51(2.31)\end{array}$ & $\begin{array}{l}\text { IMT (control } \\
\text { group: nasal } \\
\text { breathing } \\
\text { and maximum } \\
\text { exhalation) }\end{array}$ & $\begin{array}{l}\% 20 \text { MIP (during the } \\
\text { first } 2 \text {-week) } \\
\% 30 \text { MIP (after the } \\
\text { second week) } \\
8 \text { sets (in the morning) } \\
\text { and } 7 \text { sets (in the } \\
\text { afternoon) of } 1 \text { min } \\
\text { breathing exercises } \\
15 \text { min/day } \\
5 \text { days/week } \\
12 \text { weeks training }\end{array}$ & $\begin{array}{l}\text { MIP } \uparrow \text { (more in the IMT group } \\
\text { than control) } \\
\text { MEP } \uparrow \text { (no group difference) } \\
\text { MVV, PEF } \uparrow \text { (no group } \\
\text { difference) } \\
\text { TV } \uparrow \text { (only in the IMT group) } \\
\text { MBORG } \downarrow \text { (more in the IMT } \\
\text { group than control) } \\
\text { FEV1, FEF } 25-75, \text { VC, FVC } \leftrightarrow \\
\text { SF-12 } \leftrightarrow\end{array}$ \\
\hline
\end{tabular}

RCT, randomized controlled trial; RRMS, relapsing-remitting multiple sclerosis; PPMS, primary progressive multiple sclerosis; SPMS, secondary progressive multiple sclerosis; PRMS, progressive relapsing multiple sclerosis; $M I P$, maximum inspiratory pressure; $M E P$, maximum expiratory pressure; FEF $_{25-75}$ mean expiratory flow; MFIS, Modified Fatigue Impact Scale; SWAL-QOL, swallow-related quality of life; PAS, abnormal airway penetration and aspiration; SF-36, Medical Outcomes Study 36-Item Short-Form Health Survey; SF-12, Medical Outcomes Study 12-Item Short-Form Health Survey; PADS, Physical Activity Disability Scale; MSSE, Multiple Sclerosis Self-Efficacy Scale; PI, pulmonary index; MBORG, Modified Borg Dyspnea Scale; NR, not reported; $\uparrow$, increased; $\downarrow$, decreased; $\leftrightarrow$, no significant change. 
bility during quiet-deep breathing. Diaphragmatic mobility and the thickening rate evaluated by this method are reduced, and they are significantly associated with the disability of pwMS [39]. Surprisingly, diaphragm thickness is similar in pwMS to healthy individuals [39].

\section{Rehabilitation Interventions to Improve Respiratory Function}

Respiratory muscle training (RMT) is considered a promising approach for pwMS suffering from respiratory dysfunction [7]. It could be applied in the form of inspiratory muscle training (IMT), expiratory muscle training (EMT), and their combination that has advantages like taking less time, not aggravating symptoms, and easy adaptation [40]. Short and long-term RMT provides positive improvements in respiratory muscle strength, spirometry parameters, cough efficiency, swallowing, fatigue, and dyspnea in pwMS [41-45]. Benefits from RMT are greater in pwMS whose disease severity was lower [46]. However, RMT could also be applied to nonambulated pwMS, and its effects continue even after 8 weeks of training [43]. Moreover, a study showed that RMT affected aerobic capacity and physical performance [47]; another study stated it was not substantially effective [40]. According to a Cochrane review, including a limited number of studies, there was low-quality evidence that IMT was moderately effective at prescribed MIP, while EMT had no significant effect in pwMS with mild to moderate disease severity. The sustainability of IMT's positive effect, clinical significance, reflection on the quality of life, pulmonary complication, and antibiotic use are uncertain due to the large differences in follow-up periods. Therefore, it has been suggested that randomized controlled studies investigate the effectiveness of various RMT (e.g., IMT, EMT, or their combination; supervised and unsupervised; and telemedicine), determining its effectiveness according to disease severity and applying long-term measurements [48]. Table 1 presents the available studies in pwMS in detail.

It has been reported that low-intensity IMT practiced in people with chronic spinal cord injury has a protective effect on cardiac function with a contribution of the autonomic nervous system [49]. IMT manages to prevent cardiovascular diseases with increasing parasympathetic activity. It stimulates baroreflex activity by increasing venous return with enhanced intrathoracic pressure and metaboreflex threshold, leading to a decrease in the heart's sympathetic activity during rest. It also creates an oscillation effect in the Vt of the lung. The primary component that supports IMT's effect on autonomic control is the resistance of training. Thus, IMT is more supportive than nonresistance breathing exercises [50]. It has been reported that IMT improves both respiratory muscle strength and respiratory muscle endurance which is associated with functional capacity and physical performance [50]. Low-intensity IMT applied in pwMS increases inspiratory-expiratory strength more than combined RMT. In addition, this training improves respiratory functions and dyspnea more than conventional breathing exercises [45]. The reason for the decrease in dyspnea is the slowing of respiratory rate and decline in carbon dioxide production due to the improvement of respiratoryrelated parameters [51]. The most practical point of low resistance IMT enhances the respiratory system without causing fatigue [45]. This is valuable in terms of compliance and adherence in RMT. Further research is needed to explain the potential treatment mechanisms of IMT for pwMS.

Respiratory muscle endurance training applied in people with stroke and spinal cord injury improves respiratory muscle strength, lung volumes, cough efficiency, dyspnea, as well as aerobic capacity, exercise performance $[52,53]$. Nonetheless, similar to these studies, no research examines the effects of respiratory muscle endurance training in pwMS.

It has not been accurately explained to treatment mechanisms of the exercise training, which is necessary for MS management, on pulmonary function in pwMS. However, the most probable mechanism can be the indirect and direct anti-inflammatory effect controlling neuroinflammation. The reduction of visceral adiposity, which is a crucial source of inflammation, reveals the indirect effect. On the other hand, the increase in T-cells responsible for the formation of interleukin-10 and transforming growth factor beta in the immune system reveals the direct effect [54]. Exercise training provides a recurrent and short-term inflammatory stimulus that induces the body to increase $\mathrm{T}$-cell production during and after exercise. Provided that exercise is done regularly, the body can adapt to this condition and result in chronically increased T-cells [55]. Besides, it has been reported that exercise training increases oxygen distribution by regulating vasodilation and angiogenesis [56], and high-repetition low-intensity resistive and aerobic exercise positively influence heart rate variability $[57,58]$. However, it is not known whether this training conduces to alteration of the pulmonary system. 
Complementary and alternative treatment approaches are also performed to improve pulmonary dysfunction in pwMS. It has been reported that 8-week pilates training can improve aerobic capacity, balance, cognitive function, and respiratory muscle strength [59], and 16-week yoga training can also increase cough efficiency [60]. A recent study comparing the effects of yoga and pilates training in pwMS found that both methods can improve respiratory muscle strength without any significant difference [61].

It has been reported that continuous positive airway pressure, which is used in the treatment of OSA, can improve fatigue in pwMS with OSA [62], and it may have a significant effect on somnolence and sleep quality [63]. It has been shown recently that continuous positive airway pressure applied at 6 months in pwMS with fatigue and nonsevere OSA did not significantly reduce fatigue severity but significantly improved the fatigue severity and sleepiness at 3 months [64].

\section{Limitation and Recommendation}

Various exercise types that positively affect respiratory muscle strength, cough efficiency, and pulmonary volumes should be investigated to demonstrate their impact on physical performance, life expectancy, quality of life, and long-term outcomes in MS. Since RMT differs from previous studies regarding duration, intensity, and frequency, it would be helpful to determine training parameters for optimum benefits. Further studies should investigate pwMS who are wheelchair-bounded or bedridden as well as pwMS who can independently walk. In addition, no studies are comparing IMT and EMT that can be performed as a combination or separately in pwMS. Therefore, comparing these two interventions in this population of patients requires further investigation.

\section{Conclusion}

Pulmonary function is significantly affected in pwMS from the early stages of the disease and leads to respiratory muscle weakness, ineffective cough, dyspnea, and pneumonia. Exercise training, RMT, and complementary and alternative treatments such as pilates and yoga may potentially reduce respiratory problems in pwMS. However, further studies with high methodological quality and larger sample sizes are highly warranted.

\section{Conflict of Interest Statement}

The authors have no conflicts of interest to declare.

\section{Funding Sources}

The authors did not receive any funding for this paper.

\section{Author Contributions}

M.D.: conception, writing, editing, and final approval of the manuscript and accountability for the work; B.O.K.: conception, critical manuscript revision, and final manuscript approval and accountability for the work; T.K.: conception, critical manuscript revision, and final manuscript approval and accountability for the work.

\section{References}

1 Noseworthy JH, Lucchinetti C, Rodriguez M, Weinshenker BG. Multiple sclerosis. N Engl J Med. 2000 Sep;343(13):938-52.

2 Walton C, King R, Rechtman L, Kaye W, Leray E, Marrie RA, et al. Rising prevalence of multiple sclerosis worldwide: insights from the Atlas of MS, third edition. Mult Scler. 2020 Dec;26(14):1816-21.

3 Pittion-Vouyovitch S, Debouverie M, Guillemin F, Vandenberghe N, Anxionnat R, Vespignani $\mathrm{H}$. Fatigue in multiple sclerosis is related to disability, depression and quality of life. J Neurol Sci. 2006 Apr;243(1-2):39-45.

4 Siegert RJ, Abernethy DA. Depression in multiple sclerosis: a review. J Neurol Neurosurg Psychiatry. 2005 Apr;76(4):469-75.
5 Bosnak-Guclu M, Gunduz AG, Nazliel B, Irkec C. Comparison of functional exercise capacity, pulmonary function and respiratory muscle strength in patients with multiple sclerosis with different disability levels and healthy controls. J Rehabil Med. 2012 Jan; $44(1): 80-6$

6 Hirst C, Swingler R, Compston DA, BenShlomo Y, Robertson NP. Survival and cause of death in multiple sclerosis: a prospective population-based study. J Neurol Neurosurg Psychiatry. 2008 Sep;79(9):1016-21.

7 Wens I, Eijnde BO, Hansen D. Muscular, cardiac, ventilatory and metabolic dysfunction in patients with multiple sclerosis: implications for screening, clinical care and endurance and resistance exercise therapy, a scoping review. J Neurol Sci. 2016 Aug;367:107-21.
8 Asano M, Duquette P, Andersen R, Lapierre $\mathrm{Y}$, Mayo NE. Exercise barriers and preferences among women and men with multiple sclerosis. Disabil Rehabil. 2013 Mar;35(5):35361.

9 Fry D, Chiara T. Pulmonary dysfunction, assessment, and treatment in multiple sclerosis. Int J MS Care. 2010 Jan;12(3):97-104.

10 Aboussouan LS. Respiratory disorders in neurologic diseases. Cleve Clin J Med. 2005 Jun;72(6):511-20.

11 Tzelepis GE, McCool FD. Respiratory dysfunction in multiple sclerosis. Respir Med. 2015 Jun; 109(6):671-9.

12 McCool FD, Tzelepis GE. Dysfunction of the diaphragm. N Engl J Med. 2012 Mar;366(10): 932-42. 
13 Smeltzer SC, Skurnick JH, Troiano R, Cook SD, Duran W, Lavietes MH. Respiratory function in multiple sclerosis. Utility of clinical assessment of respiratory muscle function. Chest. 1992 Feb;101(2):479-84.

14 Mutluay FK, Gürses HN, Saip S. Effects of multiple sclerosis on respiratory functions. Clin Rehabil. 2005 Jun;19(4):426-32.

15 Farhat MR, Loring SH, Riskind P, Weinhouse G. Disturbance of respiratory muscle control in a patient with early-stage multiple sclerosis. Eur Respir J. 2013 Jun;41(6):1454-6.

16 Westerdahl E, Gunnarsson M, Wittrin A, Nilsagård Y. Pulmonary function and respiratory muscle strength in patients with multiple sclerosis. Mult Scler Int. 2021 Jun;2021: 5532776.

17 Andreasen AK, Jakobsen J, Petersen T, Andersen $\mathrm{H}$. Fatigued patients with multiple sclerosis have impaired central muscle activation. Mult Scler. 2009 Jul;15(7):818-27.

18 American Thoracic Society/European Respiratory Society. ATS/ERS statement on respiratory muscle testing. Am J Respir Crit Care Med. 2002 Aug;166(4):518-624.

19 Ray AD, Mahoney MC, Fisher NM. Measures of respiratory function correlate with fatigue in ambulatory persons with multiple sclerosis. Disabil Rehabil. 2015 Dec;37(26):2407-12.

20 Krishnan V, Kanekar N, Aruin AS. Feedforward postural control in individuals with multiple sclerosis during load release. Gait Posture. 2012 Jun;36(2):225-30.

21 Aguilar-Zafra S, Del Corral T, MonteroGonzález N, de-Gabriel-Hierro A, López-deUralde-Villanueva I. Urinary incontinence and impaired physical function are associated with expiratory muscle weakness in patients with multiple sclerosis. Disabil Rehabil. 2021 Jan;1-9. Epub ahead of print.

22 McCool FD. Global physiology and pathophysiology of cough: ACCP evidence-based clinical practice guidelines. Chest. 2006 Jan; 129(1 Suppl):48S-53S.

23 Levy J, Bensmail D, Brotier-Chomienne A, Butel S, Joussain C, Hugeron C, et al. Respiratory impairment in multiple sclerosis: a study of respiratory function in wheelchair-bound patients. Eur J Neurol. 2017 Mar;24(3):497502.

24 Auer RN, Rowlands CG, Perry SF, Remmers JE. Multiple sclerosis with medullary plaques and fatal sleep apnea (Ondine's curse). Clin Neuropathol. 1996 Mar;15(2):101-5.

25 Braley TJ, Segal BM, Chervin RD. Sleep-disordered breathing in multiple sclerosis. Neurology. 2012 Aug;79(9):929-36.

26 Veauthier C, Radbru H, Gaede G, Pfueller C, Dorr J, Bellmann-Strobl J, et al. Fatigue in multiple sclerosis is closely related to sleep disorders: a polysomnographic cross-sectional study. Mult Scler J. 2011 May;17(5):613-22.

27 Kaminska M, Kimoff RJ, Benedetti A, Robinson A, Bar-Or A, Lapierre Y, et al. Obstructive sleep apnea is associated with fatigue in multiple sclerosis. Mult Scler J. 2012 Aug;18(8): 1159-69.
28 Hughes AJ, Dunn KM, Chaffee T. Sleep disturbance and cognitive dysfunction in multiple sclerosis: a systematic review. Curr Neurol Neurosci Rep. 2018 Jan;18(1):2.

29 McNicholas N, Russell A, Nolan G, Tubridy N, Hutchinson M, Garvey JF, et al. Impact of obstructive sleep apnoea on cognitive function in multiple sclerosis: a longitudinal study. J Sleep Res. 2021 Jun;30(3):e13159.

30 Crawley F, Saddeh I, Barker S, Katifi H. Acute pulmonary oedema: presenting symptom of multiple sclerosis. Mult Scler. 2001 Feb;7(1): $71-2$.

31 Koseoglu BF, Gokkaya NK, Ergun U, Inan L, Yesiltepe E. Cardiopulmonary and metabolic functions, aerobic capacity, fatigue and quality of life in patients with multiple sclerosis. Acta Neurol Scand. 2006 Oct;114(4):261-7.

32 Hansen D, Wens I, Keytsman C, Verboven K, Dendale P, Eijnde BO. Ventilatory function during exercise in multiple sclerosis and impact of training intervention: cross-sectional and randomized controlled trial. Eur J Phys Rehabil Med. 2015 Oct;51(5):557-68.

33 Ranu H, Wilde M, Madden B. Pulmonary function tests. Ulster Med J. 2011 May;80(2): 84-90.

34 Pellegrino R, Viegi G, Brusasco V, Crapo R, Burgos F, Casaburi R, et al. Interpretative strategies for lung function tests. Eur Respir J. 2005 Nov;26(5):948-68.

35 Bianco A, Patanella AK, Nociti V, De Fino C, Lucchini M, Savio FL, et al. Severe dyspnoea with alteration of the diffusion capacity of the lung associated with fingolimod treatment. Mult Scler Relat Disord. 2016 Sep;9:11-3.

36 Sancho J, Servera E, Díaz J, Marín J. Predictors of ineffective cough during a chest infection in patients with stable amyotrophic lateral sclerosis. Am J Respir Crit Care Med. 2007 Jun;175(12):1266-71.

37 Srour N, LeBlanc C, King J, McKim DA. Lung volume recruitment in multiple sclerosis. PLoS One. 2013 Jan;8(1):e56676.

38 Miscio G, Guastamacchia G, Priano L, Baudo $\mathrm{S}$, Mauro A. Are the neurophysiological techniques useful for the diagnosis of diaphragmatic impairment in multiple sclerosis (MS)? Clin Neurophysiol. 2003 Jan;114(1):147-53.

39 Sahin H, Dogan A, Ekiz T. Ultrasonographic evaluation of the diaphragm thickness in patients with multiple sclerosis. Mult Scler Relat Disord. 2019 Nov;36:101369.

40 Ray AD, Udhoji S, Mashtare TL, Fisher NM. A combined inspiratory and expiratory muscle training program improves respiratory muscle strength and fatigue in multiple sclerosis. Arch Phys Med Rehabil. 2013 Oct; 94(10): 1964-70.

41 Chiara T, Martin AD, Davenport PW, Bolser DC. Expiratory muscle strength training in persons with multiple sclerosis having mild to moderate disability: effect on maximal expiratory pressure, pulmonary function, and maximal voluntary cough. Arch Phys Med Rehabil. 2006 Apr;87(4):468-73.
42 Gosselink R, Kovacs L, Ketelaer P, Carton H, Decramer M. Respiratory muscle weakness and respiratory muscle training in severely disabled multiple sclerosis patients. Arch Phys Med Rehabil. 2000 Jun;81(6):747-51.

43 Huang MH, Fry D, Doyle L, Burnham A, Houston N, Shea K, et al. Effects of inspiratory muscle training in advanced multiple sclerosis. Mult Scler Relat Disord. 2020 Jan; 37:101492.

44 Silverman EP, Miller S, Zhang Y, HoffmanRuddy B, Yeager J, Daly JJ. Effects of expiratory muscle strength training on maximal respiratory pressure and swallow-related quality of life in individuals with multiple sclerosis. Mult Scler J Exp Transl Clin. 2017 Jun;3(2): 2055217317710829.

45 Martin-Sanchez C, Calvo-Arenillas JI, Barbero-Iglesias FJ, Fonseca E, Sanchez-Santos JM, Martin-Nogueras AM. Effects of 12-week inspiratory muscle training with low resistance in patients with multiple sclerosis: a non-randomised, double-blind, controlled trial. Mult Scler Relat Disord. 2020 Nov;46:102574.

46 Martín-Valero R, Zamora-Pascual N, Armenta-Peinado J. Training of respiratory muscles in patients with multiple sclerosis: a systematic review. Respir Care. 2014 Nov; 59(11):1764-72.

47 Pfalzer L, Fry D. Effects of a 10-week inspiratory muscle training program on lower-extremity mobility in people with multiple sclerosis: a randomized controlled trial. Int J MS Care. 2011 Mar;13(1):32-42.

48 Rietberg MB, Veerbeek JM, Gosselink R, Kwakkel G, van Wegen EE. Respiratory muscle training for multiple sclerosis. Cochrane Database Syst Rev. 2017 Dec;12(12):CD009424.

49 Legg Ditterline BE, Asian SC, Randall DC, Harkema SJ, Castillo C, Ovechkin AV. Response to letter to the editor regarding "effects of respiratory training on heart rate variability and baroreflex sensitivity in individuals with chronic spinal cord injury". Arch Phys Med Rehabil. 2018 Mar;99(3):776-7.

50 Ferreira JB, Plentz RD, Stein C, Casali KR, Arena R, Lago PD. Inspiratory muscle training reduces blood pressure and sympathetic activity in hypertensive patients: a randomized controlled trial. Int J Cardiol. 2013 Jun; 166(1):61-7.

51 Parshall MB, Schwartzstein RM, Adams L, Banzett RB, Manning HL, Bourbeau J, et al. An official American Thoracic Society statement: update on the mechanisms, assessment, and management of dyspnea. Am J Respir Crit Care Med. 2012 Feb;185(4):435-52.

52 van Houtte S, Vanlandewijck Y, Kiekens C, Spengler CM, Gosselink R. Patients with acute spinal cord injury benefit from normocapnic hyperpnoea training. J Rehabil Med. 2008 Feb;40(2):119-25.

53 Kim J, Park JH, Yim J. Effects of respiratory muscle and endurance training using an individualized training device on the pulmonary function and exercise capacity in stroke patients. Med Sci Monit. 2014 Dec;20:2543-9.
Respiratory Impairment and

Rehabilitation in Multiple Sclerosis
Dubai Med J 2022;5:78-88

DOI: $10.1159 / 000521444$ 
54 Bharath LP, Ip BC, Nikolajczyk BS. Adaptive immunity and metabolic health: harmony becomes dissonant in obesity and aging. Compr Physiol. 2017 Oct; 7(4):1307-37.

55 Weinhold M, Shimabukuro-Vornhagen A, Franke A, Theurich S, Wahl P, Hallek M, et al. Physical exercise modulates the homeostasis of human regulatory $\mathrm{T}$ cells. J Allergy Clin Immunol. 2016 May;137(5):1607-10.e8.

56 Hoier B, Hellsten Y. Exercise-induced capillary growth in human skeletal muscle and the dynamics of VEGF. Microcirculation. 2014 May;21(4):301-14.

57 Murad K, Brubaker P, Fitzgerald D, Morgan T, Goff D, Soliman E, et al. Exercise training improves heart rate variability in older patients with heart failure: a randomized, controlled, single-blinded trial. Congest Hear Fail. 2012 Jul;18(4):192-7.
58 Caruso FR, Arena R, Phillips SA, Bonjorno JC Jr, Mendes RG, Arakelian VM, et al. Resistance exercise training improves heart rate variability and muscle performance: a randomized controlled trial in coronary artery disease patients. Eur J Phys Rehabil Med. 2015 Jun;51(3):281-9.

59 Abasiyanik Z, Ertekin O, Kahraman T, Yigit $\mathrm{P}$, Ozakbas S. The effects of clinical Pilates training on walking, balance, fall risk, respiratory, and cognitive functions in persons with multiple sclerosis: a randomized controlled trial. Explore. 2020 Jan;16(1):12-20.

60 Salgado BC, Jones M, Ilgun S, McCord G, Loper-Powers M, van Houten P. Effects of a 4-month Ananda Yoga program on physical and mental health outcomes for persons with multiple sclerosis. Int J Yoga Therap. 2013 Oct;23(23):27-38.
61 Abasiyanik Z, Yigit P, Ozdogar AT, Kahraman T, Ertekin O, Ozakbas S. A comparative study of the effects of yoga and clinical Pilates training on walking, cognition, respiratory functions, and quality of life in persons with multiple sclerosis: a quasi-experimental study. Explore. 2021 Sep-Oct;17(5):424-9.

62 Veauthier C, Gaede G, Radbruch H, Gottschalk S, Wernecke KD, Paul F. Treatment of sleep disorders may improve fatigue in multiple sclerosis. Clin Neurol Neurosurg. 2013 Sep; 115(9):1826-30.

63 Côté I, Trojan DA, Kaminska M, Cardoso M, Benedetti A, Weiss D, et al. Impact of sleep disorder treatment on fatigue in multiple sclerosis. Mult Scler. 2013 Apr;19(4):480-9.

64 Khadadah S, Kimoff RJ, Duquette P, Jobin V, Lapierre Y, Benedetti A, et al. Effect of continuous positive airway pressure treatment of obstructive sleep apnea-hypopnea in multiple sclerosis: a randomized, double-blind, placebo-controlled trial (SAMS-PAP study). Mult Scler. 2022 Jan;28(1):82-92. 